\title{
LOS DERECHOS HUMANOS EN EL ESTADO SOCIAL Y DEMOCRÁTICO
}

\author{
HUMAN RIGHTS IN THE SOCIAL AND DEMOCRATIC STATE \\ DIREITOS HUMANOS NO ESTADO SOCIAL E DEMOCRÁTICO
}

\author{
ALFONSO JAIME MARTínez LAZCANO \\ https://orcid.org/0000-0003-0367-4716 / alfonso.martinez@unach.mx \\ Universidad Autónoma de Chiapas - México
}

\begin{abstract}
RESUMO
A função do estado de direito democrático e social é promover o desenvolvimento humano, sendo fundamental atender a parte da população que, devido à sua situação socioeconômica, é impedida de obter por si só ou ter a possibilidade real de acessar a esses fatores essenciais, o que é viável quando o respeito pelos direitos humanos é efetivo.
\end{abstract}

Palavras-chave: Administração pública; Direito convencional; Direitos humanos; Estado social e democrático.

\section{ABSTRACT}

The function of the social and democratic rule of law is to promote human development, being basic to attend to the part of the population that due to its socioeconomic situation is prevented from obtaining by itself or having the real possibility of accessing essential factors, which is feasible to achieve when respect for human rights is effective.

Keywords: Public administration; Conventional law; Human rights; Social and democratic state.

\section{RESUMEN}

El Estado social y democrático de derecho tiene como función promover el desarrollo humano, siendo básico atender a la parte de la población que por su situación socioeconómica se encuentra impedida de obtener por sí misma o tener la posibilidad real de acceder a satisfactores primordiales, lo cual es factible lograr cuando el respeto a los derechos humanos es eficaz.

Palabras clave: Administración pública; Derecho convencional; Derechos humanos; Estado social y democrático.

\section{SUMÁRIO}

I INTRODUCIÓN; 1 ESTADO SOCIAL Y DEMOCRÁTICO DE DERECHO; 2 DERECHOS HUMANOS; 2.1

Dignidad; 2.2 Contenido de los derechos humanos; 2.2.1 ¿Qué son los derechos humanos?; 2.2.2 ¿Para quiénes son los derechos humanos?; 2.2.2.1 Derechos subjetivos; 2.2.3 ¿Cuál es el contenido de los derechos humanos?; 2.3 Derechos humanos, concepto vivo; 3 ESTADO SOCIAL Y DEMOCRÁTICO DE LOS DERECHOS HUMANOS; 4 ADMINISTRACIÓN PÚBLICA; 4.1 Coordinación de departamentos en la administración pública; 4.2 Participación de la mujer en la administración pública; CONCLUSIÓN; REFERENCIAS. 


\section{INTRODUCIÓN}

El determinar cuáles son las tareas principales del Estado, es una cuestión esencial para cumplir con las obligaciones de promover, respetar, proteger y garantizar los derechos humanos, por un lado, hay sistemas, con sus matices, en el que las funciones del Estado sólo están destinadas a asegurar las libertades de los miembros de la sociedad, absteniéndose de intervenir en la distribución de la riqueza, dejando al mercado esta actividad, donde se fijan los precios de los productos y servicios, en base a la oferta, la demanda y la especulación.

En este tipo de gobierno el oficio exclusivo del Estado es la seguridad pública, basado en ideas políticas que sustentan los regímenes de corte liberal y del llamado neoliberalismo.

El liberalismo es partidario de la economía de mercado; como teoría política es simpatizante del Estado gobierne lo menos posible o, como se dice hoy, del Estado mínimo (reducido al mínimo indispensable). ${ }^{1}$

En Latinoamérica el grado de desigual social es alto, de acuerdo con el coeficiente Gini, que un parámetro diseñado por el estadístico Corran Gini (1884-1965) para medir las formas de distribución de la riqueza en las sociedades por los ingresos.

El reporte "Perspectivas económicas de América Latina 2019", la región posee un coeficiente de Gini de 46.2 y tiene 9.7 puntos por encima de los países de la Organización para la Cooperación y el Desarrollo Económicos (OCDE). ${ }^{2}$

${ }^{1}$ BOBBIO, Norberto, El futuro de la democracia, Fondo de Cultura Económica, México, 1991, p. 89.

2 ZUNIGA QUEVEDO, Javier, La desigualdad en América Latina, Panorámica, Disponible en: https: //www.panoramical.eu/columnas/la-desigualdad-en-america-latina/, consulta 15/05/2020. 


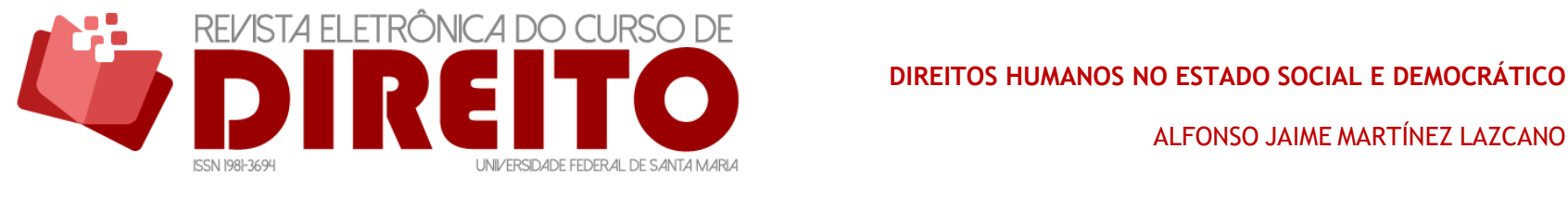

Imagen 1 - Coeficiente de Gini en América Latina

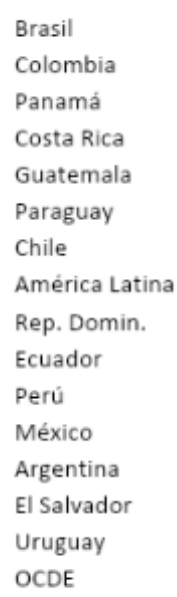

0

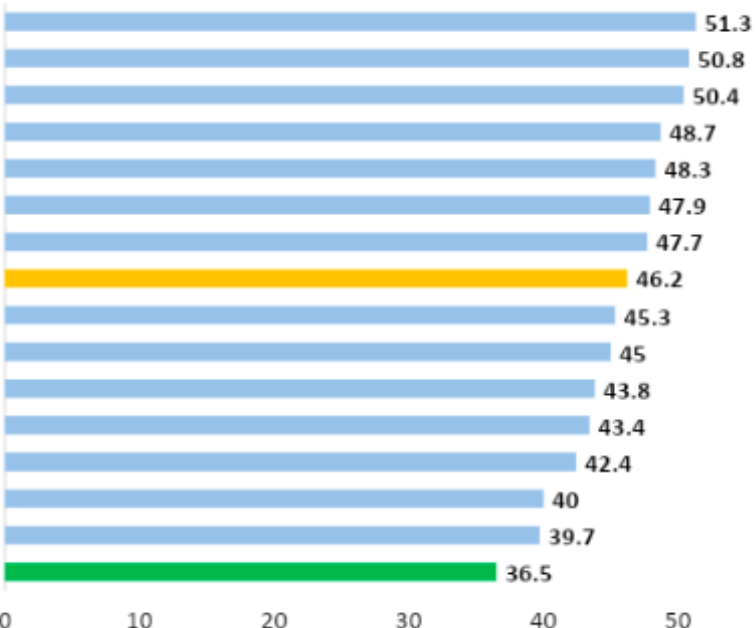

50

Fuente: CEPAL, 2019.

Los de menor desigualdad de ingresos en América Latina son Argentina (42.4), El Salvador (40) y Uruguay (39.7). ${ }^{3}$

El liberalismo como ideología nace inspirado en el individualismo tiene sus raíces en la reforma protestante del Siglo XVI, en las revoluciones inglesas del Siglo XVII y en la influencia de los pensadores de los Siglos XVII y XVIII. ${ }^{4}$

La subordinación de los Estados nacionales a las exigencias de la libertad económica de los dueños de la economía, acompañada de la supresión de todas las reglamentaciones sobre los mercados, comenzando por: a) el mercado de trabajo; b) la prohibición de incurrir en los déficits y en la inflación; c) la privatización generalizada de los servicios públicos; y d) la reducción de los gastos públicos y sociales. ${ }^{5}$

Esta ausencia del Estado ocasiona que se constituyan grupos privados como factores reales del poder, de manera paralela a éste, y éstos van sustituyendo al Estado en las tareas sociales a los intereses del mercado, inclusive al grado llegar a convertirse en un poder transnacional.

\footnotetext{
3 Ídem.

${ }^{4}$ VARGAS HERNÁNDEZ, José Guadalupe, Liberalismo, neoliberalismo y postneoliberalismo, 2007, p. 2, (Disponible en: http: //200.49.237.216/bitstream/123456789/3361/1/Vargas\%20Hernandez\%20\%20liberalismo.pdf, consultado el 12/06/2019).

${ }^{5}$ BOURDIEU, Pierre, La esencia del neoliberalismo, Revista Colombiana de educación, 1997, no. 35, (Disponible en: https://revistas.pedagogica.edu.co/index.php/RCE/article/view/5426/4453, consultado el 15/12/2015).
} 
Por otra parte, hay sistemas en los que se procura promover el desarrollo general, en el cual el Estado participa en la planificación de actividades económicas, sociales y culturales, de forma especial las destinadas a aquella parte de la población que se encuentra en desventaja por la situación socioeconómica, que en las sociedades concentra a la mayoría de las personas, por no contar con el acceso a los beneficios indispensables para el progreso, impulsando políticas fiscales de redistribución de la riqueza pública, así es posible denominar a esta organización como Estado social de derecho.

El desarrollo humano consiste en un pleno ejercicio de capacidades, la constitución de una sociedad justa debe ofrecer igualdad de oportunidades para que todos los miembros puedan tener acceso al progreso, asumiendo como contrapartida el ejercicio de sus deberes y responsabilidades hacia los demás. ${ }^{6}$

La eficacia de los derechos humanos requiere que el Estado se involucre en un infinidad de tareas, para que cada persona esté en posibilidades de aspirar a una vida digna, como es la protección a la salud, al acceso a la educación, a la tecnología, contar con trabajo y obtener como resultado de su esfuerzo un salario que le permita adquirir bienes y servicios, que representen por lo menos el mínimo vital, disfrutar de vivienda, contar con agua potable, energía eléctrica, vivir en un entorno limpio, respeto a la cultura, a la recreación, lo que en conjunto constituye la dignidad humana, a través de la solidaridad social, para estar en condiciones de vivir con libertad real e "igualdad material", 7 lo que no es factible lograr, si se deja este conjunto de satisfactores a lo que determine el mercado, porque su finalidad es concentrar la riqueza en pocas manos, pagar lo menos posible por el trabajo y establecer como regla la no estabilidad laboral, entre otras políticas contrarias al desarrollo humano.

Estas exigencias para el Estado tienen como fuentes principales tanto el derecho constitucional como el derecho convencional, así la revitalización de los derechos humanos es contemporánea a la deslegitimación discursiva del neoliberalismo. ${ }^{8}$

\footnotetext{
${ }^{6}$ TAMI, Felipe; SALVIA, Agustín, Introducción: desarrollo humano y deuda social, en Barómetro de la Deuda Social Argentina, 2004, vol. 1, p. 12, (Disponible en: https: / /www.aacademica.org/agustin.salvia/181.pdf, consultado el 15/10/2019).

7 Pensar en la igualdad de todos los integrantes de la sociedad es una falacia, porque está integrada de manera heterogénea, que impide de manera real que todos tengan las mismas posibilidades de desarrollo, aunado a las características y talentos de cada individuo, lo que es fundamental es que cada miembro de la colectividad cuente con las condiciones por lo menos mínimas para desarrollar sus capacidades.

8 STOLKINER, Alicia, Derechos humanos y derecho a la salud en América Latina: la doble faz de una idea potente, Medicina social, 2010, vol. 5, no. 1, pp. 89-95.
} 
Desde la instalación del sistema neoliberal en Chile es clara la reducción de la importancia del Estado como garante de calidad de vida, versus la relevancia del mercado en temas alguna vez considerados como derechos sociales entre los que se cuenta la educación?.

\section{ESTADO SOCIAL Y DEMOCRÁTICO DE DERECHO}

Estado social y democrático de derecho surge por primera vez como referencia denominativa de la organización política, económica y social de una nación, dentro del contexto de la revolución francesa de 1848, que culmina con la instauración de la Segunda República, fundamentada en valores, principios e instituciones colectivas, como la fraternidad, el bienestar común y la asociación, que permiten la configuración de derechos económicos, sociales y culturales a favor de los ciudadanos, incluyendo, por vez primera, el derecho al trabajo como un derecho fundamental. ${ }^{10}$

El Estado social de derecho es la respuesta a una diversidad social creciente, a través de una reglamentación que involucra a toda la sociedad en una interacción ideológica del Estado liberal y el Estado bienestar, es una manifestación propia de las relaciones entre los particulares y el Estado ${ }^{11}$.

Osvaldo Larrañaga cita las tres clasificaciones de Esping Andersen: El Estado bienestar residual o liberal de la política social, se focaliza en grupos que experimentan carencias demostrables; en el Estado social corporativo la redistribución de ingresos se realiza al interior de estratos ocupacionales; mientras que en el caso del Estado bienestar social demócrata, se busca garantizar estándares igualitarios en el acceso a un conjunto de bienes y servicios que se asignan por fuera del mercado. ${ }^{12}$

El Estado social y democrático de derecho tiene como función promover el desarrollo humano, siendo básico atender a la parte de la población que por su situación socioeconómica se

\footnotetext{
9 ÁlVAREZ-BRAVO, Paulo, Educación y derechos humanos en Chile, una relación necesaria, Revista Educación, 2019, pp. 592, 593 y 604.

10 BAUTISTA, Felix, Estado social y democrático de derecho, (Disponible en: https: / / istindiario.com/puntos-de-vista/2012/02/01/220146/estado-social-y-democratico-de-derecho, consultado el 18/06/2019).

${ }^{11}$ GUTIÉRREZ, Diana Carolina Sánchez; RICAUTE, Sandra Patricia; CASTILLO, David Felipe, Compatibilidad del principio de sostenibilidad fiscal y el concepto de estado social de Derecho en Colombia, In Vestigium Ire, 2012, vol. 5, no. 1, p. 87.

12 LARRAÑAGA, Osvaldo, et al. ¿Qué puede esperarse de la política social en Chile?, Documento de Investigación, Departamento de Economía, Universidad de Chile, 2007, p. 4.
} 
encuentra impedida de obtener por sí misma o tener la posibilidad real de acceder a satisfactores primordiales.

El mercado se institucionalizó paulatinamente como gran regulador de la vida económica, lo que procuró una relativa automatización de las esferas públicas y privadas. Los tres ciclos o estadios de la moderna ciudadanía correspondieron, según Marshall, a los diversos períodos de constitucionalización de los derechos 'civiles (siglo XVIII, con la superación de la organización estamental del 'Antiguo Régimen', tras las revoluciones inglesa, norteamericana y francesa), 'políticos' (siglo XIX, con la institucionalización del liberalismo democrático y la representación electoral), y 'sociales' (siglo XX, con la consolidación del igualitarismo en los estados del bienestar en las democracias industriales). En sentido general, el proceso de modernización en el mundo occidental comportó el paso de los criterios de adscripción a los criterios de logro. ${ }^{13}$

El Modelo constitucional de Estado social de derecho es de carácter republicano, basado en la separación de poderes, en la legitimación democrática del poder, en la participación democrática en la conformación del mismo, en el constitucionalismo, la estatalidad de los derechos fundamentales y el Estado social de bienestar. ${ }^{14}$

En la Constitución mexicana no se dice de manera expresa, como sí en la Carta Magna española, que expresa que se constituye en un Estado social y democrático de derecho, que propugna como valores superiores la libertad, la justicia, la igualdad y el pluralismo político ${ }^{15}$. Sin embargo, el contenido prevé la actuación del Estado como regulador de las actividades básicas que le corresponden al Estado social y democrático de derecho, como se desprende del siguiente criterio judicial:

Existe un ámbito en donde el Estado vigila la desviación de la conducta prescrita jurídicamente no sólo en su calidad de Estado policía o vigilante, sino en su papel de Estado regulador, esto es, en ejercicio de su facultad constitucional de planificación de actividades económicas, sociales y culturales, para la realización de ciertos fines, que no podrían cumplirse si se dejaran al libre intercambio de las personas, a quienes, por tanto, no se les concibe como sujetos pasivos de una potestad coactiva, sino como sujetos participantes y activos de un cierto sector o mercado regulado. Así, esta nota planificadora o reguladora ha marcado el tránsito de un modelo de Estado de derecho, en donde el Estado tenía una

13 MORENO, Luis, Ciudadanía, desigualdad social y Estado del bienestar, 2003, (Disponible en: https: / / core.ac.uk/download/pdf/36013923.pdf, consultado el 12/11/2019).

${ }_{14}$ MORA, Patricia Bastidas, El modelo constitucional del Estado Social y democrático de derecho, sus desafíos y la constitucionalización del proceso, Revista Via luris, 2009, no. 7, pp. 45-59.

15 Cfr. PECES-BARBA MARTíNEZ, Gregorio. Los valores superiores. 1987, p.375. (Véase en: https://earchivo.uc3m.es/bitstream/handle/10016/10389/valores_Peces_AFD_1987.pdf?sequence=1,, consulta $12 / 12 / 2019)$. 
función subsidiaria y secundaria para intervenir en caso de una ruptura del orden público, al Estado social de derecho, en donde el Estado tiene una función central de rectoría económica, cuyo fundamento se encuentra conjunta y principalmente en los artículos 25 y 28 de la Constitución Política de los Estados Unidos Mexicanos. Ahora bien, debe destacarse que las sanciones impuestas en este sector presuponen un contexto diferenciado, en el que los particulares se ubican como sujetos activos y participantes de ciertos mercados, o como prestadores de un servicio concesionado o permisionarios para la explotación de un bien público, por lo que su conducta está regulada por normas, que si bien tienen como marco una ley que establece las líneas regulativas principales, también se integra por una pluralidad de instrumentos normativos, como son reglamentos, normas oficiales mexicanas u otras de naturaleza administrativa, que son requeridas por la regulación especializada técnica y flexible para la realización de ciertos fines de políticas públicas, establecidos en la Constitución o en las leyes las que, en contrapartida, se han de desarrollar por órganos administrativos igualmente especializados y técnicos. De ahí que el modelo de Estado regulador supone un compromiso entre principios: el de legalidad, el cual requiere que la fuente legislativa, con legitimidad democrática, sea la sede de las decisiones públicas desde donde se realice la rectoría económica del Estado, y los principios de eficiencia y planificación que requieren que los órganos expertos y técnicos sean los que conduzcan esos principios de política pública a una realización óptima, mediante la emisión de normas operativas que no podrían haberse previsto por el legislador, o bien, estarían en un riesgo constante de quedar obsoletas, pues los cambios en los sectores tecnificados obligaría a una adaptación incesante poco propicia para el proceso legislativo y más apropiado para los procedimientos administrativos. ${ }^{16}$ (Subrayado agregado)

\section{DERECHOS HUMANOS}

Los derechos humanos tienen como cimiento y explicación el respeto a la singularidad de cada ser humano en lo personal y como integrante de un grupo social determinado, ese respeto es la dignidad. En lo individual cuenta con la capacidad de razonar, voluntad, libertad, igualdad e historicidad. ${ }^{17}$

La dignidad humana es el reconocimiento de que la persona es algo especial y extraordinario, debido a su racionalidad y a todo lo que ello implica ${ }^{18}$.

El ser humano tiene la posibilidad de pensar, conocer, comprender, reflexionar a diferencia de todas las demás especies en el planeta. Al tener libertad puede decidir, elegir y actuar de acuerdo a sus intereses, ideas y convicciones en base a su voluntad. A pesar de las

\footnotetext{
${ }^{16}$ Tesis: 1a. CCCXVII/2014 (10a.), Gaceta del Semanario Judicial de la Federación, Libro 10, septiembre de 2014, Tomo I, p. 574.

17 CARPIZO, Jorge, Los derechos humanos: naturaleza, denominación y características. Cuestiones constitucionales, 2011, no. 25, pp. 3-29.

18 Ídem.
} 
diferencias biológicas y anatómicas naturales entre los seres humanos, que son las singularidades de cada uno, todos deben ser tratados con dignidad, porque en esencia conforman la misma familia, así entre semejantes el trato debe ser igual desde el punto de vista jurídico, además de proteger con mayor cuidado a los que son más vulnerables como consecuencia de la realidad de las condiciones en las que se vive o se subsiste.

Por su inteligencia el ser humano es capaz de conocer y entender el mundo en que vive y del que forma parte, es capaz de conocerse a sí mismo y de reflexionar sobre las razones de su existencia ${ }^{19}$.

\subsection{Dignidad}

La Suprema Corte de Justicia de la Nación ha sostenido que la dignidad humana permea en todo el ordenamiento, constituye una norma jurídica que consagra un derecho fundamental a favor de las personas y no una simple declaración ética, no se identifica ni se confunde con un precepto meramente moral, sino que se proyecta como un bien jurídico circunstancial al ser humano, merecedor de la más amplia protección jurídica, reconocido actualmente en los artículos 10., último párrafo; 20., apartado A, fracción II; 3o., fracción II, inciso c); y 25 de la Constitución Política de los Estados Unidos Mexicanos, inherente a toda persona, por el mero hecho de serlo, a ser tratada como tal y no como un objeto, a no ser humillada, degradada, envilecida o cosificada ${ }^{20}$.

La dignidad es una cualidad que se tiene en todas las circunstancias de la vida, que por ningún suceso se pierde, a pesar de que limiten sus derechos a las personas, por ejemplo, por encontrarse en prisión.

El aislamiento prolongado y la incomunicación coactiva a los que se ve sometida la víctima representan, por sí mismos, formas de tratamiento cruel e inhumano, lesivas de la integridad psíquica y moral de la persona y del derecho de todo detenido al respeto debido a la dignidad inherente al ser humano ${ }^{21}$.

La Declaración Americana de los Derechos y Deberes del Hombre utiliza la palabra dignidad en tres ocasiones: dos en el preámbulo y uno en el artículo XXIII:

\footnotetext{
19 QUINTANA ROLDÁN, Carlos y SABINO PENICHE, Norma, Derechos humanos, Porrúa, México, 2013, p. 34.

20 Tesis: 1a. /J. 37/2016 (10a.), Gaceta del Semanario Judicial de la Federación, Libro 33, agosto de 2016, Tomo II, p. 633.

${ }^{21}$ CORTE IDH. Caso Cantoral Benavides Vs. Perú. Fondo. Sentencia de 18 de agosto de 2000. Serie C No. 69, Párrafo 83.
} 
[...] Todos los hombres nacen libres e iguales en dignidad y derechos y, dotados como están por naturaleza de razón y conciencia, deben conducirse fraternalmente los unos con los otros. [...]

El cumplimiento del deber de cada uno es exigencia del derecho de todos. Derechos y deberes se integran correlativamente en toda actividad social y política del hombre. Si los derechos exaltan la libertad individual, los deberes expresan la dignidad de esa libertad. [...]

Artículo XXIII. Toda persona tiene derecho a la propiedad privada correspondiente a las necesidades esenciales de una vida decorosa, que contribuya a mantener la dignidad de la persona y del hogar.

La Declaración Universal de Derechos del Hombre ${ }^{22}$ utiliza el concepto de dignidad en cinco ocasiones: dos en el preámbulo y en tres artículos:

[...] Considerando que la libertad, la justicia y la paz en el mundo tienen por base el reconocimiento de la dignidad intrínseca y de los derechos iguales e inalienables de todos los miembros de la familia humana. [...]

Considerando que los pueblos de las Naciones Unidas han reafirmado en la Carta su fe en los derechos fundamentales del hombre, en la dignidad y el valor de la persona humana y en la igualdad de derechos de hombres y mujeres, y se han declarado resueltos a promover el progreso social y a elevar el nivel de vida dentro de un concepto más amplio de la libertad. [...]

Artículo 1 Todos los seres humanos nacen libres e iguales en dignidad y derechos y, dotados como están de razón y conciencia, deben comportarse fraternalmente los unos con los otros. [...]

Artículo 22 Toda persona, como miembro de la sociedad, tiene derecho a la seguridad social, y a obtener, mediante el esfuerzo nacional y la cooperación internacional, habida cuenta de la organización y los recursos de cada Estado, la satisfacción de los derechos económicos, sociales y culturales, indispensables a su dignidad y al libre desarrollo de su personalidad.

Artículo 23 Toda persona que trabaja tiene derecho a una remuneración equitativa y satisfactoria, que le asegure, así como a su familia, una existencia conforme a la dignidad humana y que será completada, en caso necesario, por cualesquiera otros medios de protección social.

Pacto Internacional de Derechos Civiles y Políticos y el Pacto Internacional de Derechos Económicos, Sociales y Culturales, en la parte sus preámbulos declaran:

[...] base el reconocimiento de la dignidad inherente a todos los miembros de la familia humana y de sus derechos iguales e inalienables... Reconociendo que estos derechos se derivan de la dignidad inherente a la persona humana [...].

22 La Asamblea General, después de celebrar más de 80 reuniones y presentar 168 enmiendas, tras el rechazo de la propuesta soviética de retrasar un año la aprobación del texto, aprobó la Declaración Universal de Derechos Humanos de 10 de diciembre de 1948, por la resolución 217. El texto se aprobó por 48 votos a favor, ninguno en contra y 8 abstenciones. Hubo dos ausencias. La Asamblea General estaba integrada entonces por 58 Estados. BALLESTEROS LLOMPART, Jesús, et. al., Derechos Humanos, Universidad de Valencia, Valencia, 2007, p. 57. 


\subsection{Contenido de los derechos humanos}

Imagen 2 - ¿Qué son los derechos humanos?

\section{¿Qué son? \\ ¿Para quién son? \\ ¿Cuál es su contenido?}

Fuente: elaboración propia.

Para la mejor comprensión de los derechos humanos se debe responder las siguientes interrogantes: ¿qué son?, ¿a quién están dirigidos a proteger? y ¿cuál es el contenido de éstos?

\subsection{1 ¿Qué son los derechos humanos?}

Son las prerrogativas básicas ${ }^{23}$ cuya finalidad es alcanzar las potencialidades individuales y colectivas fundadas en la dignidad humana, cuyo principal obligado es el Estado, así como cualquier persona que tenga poder de afectación. Hay infinidad de conceptos e ideas de lo que son los derechos humanos, entre ellos se encuentran:

Los derechos humanos son garantías esenciales para que podamos vivir como seres humanos. Sin ellos no podemos cultivar ni ejercer plenamente nuestras cualidades, nuestra inteligencia, talento y espiritualidad ${ }^{24}$.

Los derechos humanos son garantías jurídicas universales que protegen a individuos y grupos contra acciones que interfieran en sus libertades fundamentales y en la dignidad humana. ${ }^{25}$

Los derechos humanos son el conjunto de prerrogativas inherentes a la naturaleza de la persona, cuya realización efectiva resulta indispensable para el desarrollo integral del individuo que vive en una sociedad jurídicamente organizada. ${ }^{26}$

\footnotetext{
${ }^{23}$ En el derecho internacional de los derechos humanos o derecho convencional de los derechos humanos se establecen estándares mínimos de protección.

${ }^{24}$ ONU, Derechos Humanos, (Disponible en: un.org/es/rights/overview, consultado el 25/01/2018).

25 Organización Mundial de la Salud, Derechos humanos. Temas de salud, (Disponible en: http://www.who.int/topics/human_rights/es/, consultado el 28/01/2018).

26 EYNER ISAZA, Henry, Los derechos humanos y Sistema Interamericano, ediciones Nueva Jurídica, Bogotá, 2014, p. 23.
} 
Los derechos humanos son, de acuerdo con diversas filosofías jurídicas, aquellas libertades, facultades, instituciones o reivindicaciones relativas a bienes primarios o básicos que incluyen a toda persona, por el simple hecho de su condición humana, para la garantía de una vida digna. Son independientes de factores particulares como el estatus, sexo, etnia o nacionalidad; y son independientes $\mathrm{o}$ no dependen exclusivamente del ordenamiento jurídico vigente. Desde un punto de vista más relacional, los derechos humanos se han definido como las condiciones que permiten crear una relación integrada entre la persona y la sociedad, que permita a los individuos ser personas, identificándose consigo mismos y con los otros ${ }^{27}$.

Aquellos derechos que tienen todas las personas por el solo hecho de ser tal, y que les permite su máxima realización material y espiritual, con responsabilidad para su propia comunidad ${ }^{28}$.

\subsection{2 ¿Para quiénes son los derechos humanos?}

Los derechos humanos están dirigidos de forma exclusiva, sin distinción alguna, a todos los seres humanos, independientemente de las circunstancias de cada persona y situación.

Los derechos humanos son derechos inherentes a todos los seres humanos, sin distinción alguna de nacionalidad, lugar de residencia, sexo, origen nacional o étnico, color, religión, lengua, o cualquier otra condición. Todos tenemos los mismos derechos humanos, sin discriminación alguna ${ }^{29}$.

Si bien existen ideas para incluir su protección en esta categoría de derechos a los animales no humanos, también lo es que la propia naturaleza del ser humano se distingue de las demás especies por sus necesidades específicas al ser un sujeto de razón y voluntad, por lo que los animales no humanos deben ser respetados como cualquier ser vivo, incluyendo las plantas, de acuerdo a la propia condición que tiene en la naturaleza.

Los derechos humanos son una especie de derechos subjetivos. Los derechos subjetivos se constituyen por un vínculo jurídico entre dos partes generalmente, una llamada acreedor, quien tiene la facultad de exigir a otra nombrada deudora una prestación de dar, hacer o no hacer.

27 ZAMUDIO, Teodora, Historia de los Bio-Derechos y del pensamiento bioético, Derechos humanos y pactos internacionales, (Disponible en: http: //www.bioetica.org/cuadernos/contenidos/pactos.htm, consultado el 12/11/2017).

28 GALIANO HAENCH, José, Derecho humanos. Teoría, historia, vigencia y legislación, LOM-ARCIS Universidad, Santiago de Chile, 1998, p. 35.

$29 \mathrm{ONU}$, Oficina del Alto Comisionado, Derechos humanos. Qué son los derechos humanos, (Disponible en: http: //www.ohchr.org/SP/Issues/Pages/WhatareHumanRights.aspx, consultado el 30/01/2018). 
Los derechos humanos para ser reales deben tener un sujeto o sujetos destinados a cumplirlos, por ellos se dice que son derechos subjetivos.

Los derechos subjetivos son estudiados inicialmente por el derecho civil, cuya fuente esencial de la obligación nace por un acuerdo de voluntades, así Gutiérrez y González habla del concepto de derecho personal convencional o derecho de crédito convencional como:

La necesidad jurídica que tiene una persona a la que se denomina obligadodeudor, de cumplir voluntariamente a favor de otra persona, a la que se le denomina acreedor, que le puede exigir una prestación de carácter patrimonial (pecuniaria o moral) ${ }^{30}$.

Esta teoría es criticada por considerar que los derechos humanos son inalienables.

\subsection{3 ¿Cuál es el contenido de los derechos humanos?}

Los derechos humanos constantemente están expendiendo su contenido, resultado de la permanente evolución.

El contenido de los derechos humanos puede ser representado por un edificio en constante construcción, por cuya puerta se introducen un conjunto de libertades y prestaciones de forma sucesiva a la par de la evolución de las sociedades, así han llegado a cimentar diferentes pisos dependiendo el grado epistémico ${ }^{31}$ : derechos civiles y políticos; derechos sociales económicos y culturales; derechos al desarrollo, a la paz, la equidad de género; al medio ambiente adecuado, entre otros.

Así el contenido de los derechos humanos no está estancado sino en constante transformación, conforme van surgiendo adversidades se construyen nuevas respuestas; cuando se refutan las logradas se tiende a fortalecer los cimientos.

Concepto vivo, que no puede considerarse elaborado de una vez por todas, de una vez para siempre de forma completa, acabada y definitiva. Por el contrario, la noción de derechos humanos evoluciona con el devenir histórico, tanto en lo

${ }^{30}$ GUTIÉRREZ Y GONZÁLEZ, Ernesto, El patrimonio, Porrúa, México, 1995, p. 207.

31 Para Foucault, las ciencias humanas tal y cómo las conocemos hoy, se han desarrollado en el desplazamiento de un discurso por otro, de una episteme por otra. La formación de un discurso, depende estrechamente de la formación de una episteme. Las tres epistemes que Foucault pretende desentrañar son: el Renacimiento, la Época Clásica y la Modernidad. GALLARDO LEÓN, Ernesto, El problema de la representación en El Quijote, en Michel Foucault, Reflexiones sobre el saber, el poder, la verdad y las prácticas de sí, UNAM, México, 2008, p. 7. 
que respecta a las connotaciones del concepto, a sus rangos, caracteres, notas o determinaciones; como en lo que respecta a su extensión ${ }^{32}$.

\subsection{Derechos humanos, concepto vivo}

Toda disposición o acto de protección que establezca límites contra el abuso de quienes detentan el poder para no afectar a la población que puede ser vulnerada; así como las exigencias jurídicas de crear las condiciones indispensables para garantizar la subsistencia humana con dignidad; el respeto a las diversas formas de pensar o preferencias, sin distinción alguna por motivos de raza, sexo, idioma, nacionalidad, hábitos, religión o de cualquier otra índole, son en esencia el germen o modalidades de lo que hoy llamamos derechos humanos.

Los derechos humanos no han surgido por generación espontánea, son resultado de las reacciones sociales a las arbitrariedades de quienes ejercen el poder sobre el resto de la población, en diferentes momentos y lugares, los derechos humanos se han generado para rebelarse ante las injusticias.

Las formas cambiantes de cómo debe ser el trato social a los semejantes ha sido consecuencia de la evolución de las sociedades, así como los retos que genera, ahora es posible discutir sobre si el acceso a internet debe ser libre o neutral o estar restringido, en su momento se cuestionó si debería limitarse el poder absoluto al Rey o se pensó qué medidas tomar después de la Segunda Guerra Mundial para que no se repitieran los horrores de tremenda crisis humanitaria, como prevenir sucesos como el trágico 11 de septiembre en los Estados Unidos, hoy se debate qué aspectos debe incluir y excluir la justicia transicional en Colombia, entre otros capítulos más de la historia del hombre.

A estos capítulos relevantes de la historia del hombre se le conoce como historicidad, los cuales provocan, en no pocos sucesos el cambio de paradigma.

Los cambios de paradigmas se dan porque el ser humano evoluciona, hablar hoy que la definición de matrimonio no se limita a la unión de un solo hombre con una sola mujer como antaño, inclusive se ha reconocido el matrimonio colectivo o entre personas del mismo sexo, por otra parte, se precisa que los órganos jurisdiccionales nacionales en algunos casos ya no tienen la última palabra y que las constituciones nacionales no son tan supremas como antes.

El destacado jurista Jorge Carpizo distingue los aspectos que para él comprende la historicidad:

32 BALLESTEROS LLOMPART, Jesús; FERNÁNDEZ RUIZ- GÁLVEZ, Encarnación y GARIBO PEYRó, Ana Paz, Derechos humanos, Universitat de Valéncia, España, 2007, p. 9. 
La historicidad se refiere a tres aspectos diversos: a) la evolución de la civilización; b) nuevos problemas, necesidades y retos, y c) el contexto social y cultural de cada país ${ }^{33}$.

La historia de los derechos humanos no es lineal o progresiva, porque no significa que en cada etapa de la humanidad se erradique de manera definitiva las trasgresiones anteriores a pesar de que se cree legislación para ello, la inequidad es cíclica, hoy gobiernos que se sustentan en sus constituciones como regímenes democráticos y reconocen los derechos humanos, no garantizan la eficacia en la vida social, sino por el contrario, algunos de forma sistemática o generalizada violan derechos humanos, como es el caso de Venezuela, Nicaragua, México, entre otros.

La idea de los derechos humanos por lo mismo es una idea en constante desarrollo, es un concepto vivo, histórico y en evolución.

La noción de derechos humanos evoluciona con el devenir histórico, tanto en los que respecta a las connotaciones del concepto, a sus rasgos, caracteres, notas o determinaciones, como en lo que respecta a su extensión ${ }^{34}$.

\section{ESTADO SOCIAL Y DEMOCRÁTICO DE LOS DERECHOS HUMANOS}

El Estado nacional se ha ido transformando a través del derecho convencional de los derechos humanos, principalmente en un ente cuya tarea principal es tutelar dentro de su jurisdicción los derechos humanos de la población. Esta función se ha ido dinamizando y perfeccionando no por las disposiciones internas, sino por los tratados internacionales, encauzando la labor de Estado a tareas que antes eran consideradas programáticas, de manera general, sin instrumentos claros de aplicación, por ejemplo, los derecho económicos, sociales y culturales no se pensaba que fuesen de exigencia inmediata, sólo se decía que los derechos humanos eran de todos, ahora se habla de derechos para los niños, niñas, adolescentes, personas mayores, poblaciones indígenas, entre otras, instrumentos como la consulta directa, previa, libre e informada, así el consentimiento informado como parte del derecho a la protección de la salud.

33 CARPIZO, Jorge, Los derechos humanos: naturaleza, denominación y características, Cuestiones constitucionales, 2011, no. 25, pp. 3-29.

${ }^{34}$ BALLESTEROS LLOMPART, Jesús, et. al., Derechos Humanos, Universidad de Valencia, Valencia, 2007, p. 9. 
El Estado social y democrático de los derechos humanos es una evolución del Estado social y democrático, porque tiene una gran influencia del derecho convencional de los derechos humanos y no sólo del derecho interno.

Hoy, las fuentes jurídicas donde se encuentran plasmados los derechos humanos son diversas, no sólo en las leyes, en las constituciones, en las convenciones, también en las interpretaciones a estos instrumentos que realizan los órganos jurisdiccionales nacionales y convencionales, por lo cual, son instrumentos vivos, en evolución, en desarrollo como respuesta a la vicisitudes reales que enfrenta el ser humano en la realidad.

La Corte ha establecido, al igual que el Tribunal Europeo de Derechos Humanos, que los tratados de derechos humanos son instrumentos vivos, cuya interpretación tiene que acompañar la evolución de los tiempos y las condiciones de vida actuales. Tal interpretación evolutiva es consecuente con las reglas generales de interpretación consagradas en el artículo 29 de la Convención Americana, así como las establecidas por la Convención de Viena sobre el Derecho de los Tratados ${ }^{35}$.

El impacto de la noción de derechos humanos al ser un concepto histórico, no siempre ha existido como tal y con las dimensiones que en el presente tiene, es factible decir que nos encontramos en una etapa de positivación de los derechos humanos, que se inicia a partir de la Declaración Universal de los Derechos Humanos, primero como una fuente ética y posteriormente jurídica, que ha dado como resultado múltiples tratados internacionales, así como organismos a nivel universal y regional, cuya función principal es la eficacia de los derechos humanos.

En el continente americano, por ejemplo, el Sistema Interamericano de Derechos Humanos (SIDH) es un ejemplo de la noción en desarrollo constante de los derechos humanos.

El SIDH es abierto y dinámico porque no sólo está conformado con las normas, principios y directrices plasmados en los tratados internacionales, sino su alcance se va nutriéndolo con la interpretación y aplicación que hacen las instituciones de supervisión, esencialmente la Corte IDH $^{36}$.

35 CORTE IDH. Caso Atala Riffo y Niñas Vs. Chile. Fondo, Reparaciones y Costas. Sentencia del 24 de febrero de 2012. Serie C No. 239, Párrafo 83.

${ }^{36}$ MARTÍNEZ LAZCANO, Alfonso Jaime, Sistemas regionales de protección de derechos humanos, Ediciones Nueva Jurídica, Bogotá, 2015, p. 185. 
Imagen 3 - La máquina de los derechos humanos.

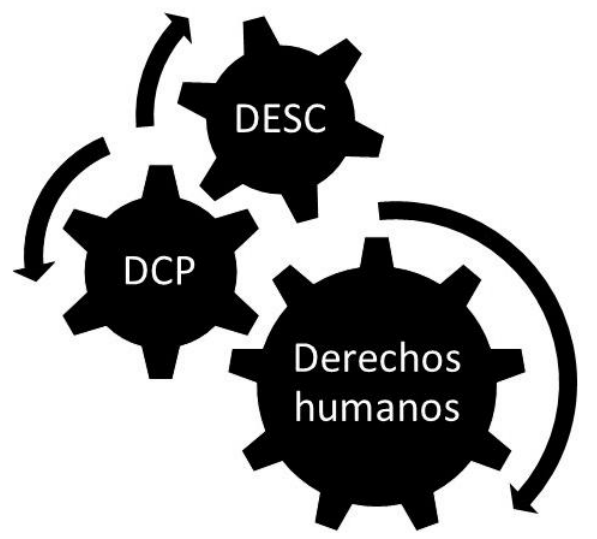

Fuente: elaboración propia.

Un punto importante es que los derechos humanos al ser un concepto vivo, en su campo o perímetro van sumando a esta categoría nuevos derechos, es decir tiene un efecto expansivo de protección, poco a poco su manto va creciendo, ahora es factible exigir la previa consulta a las poblaciones indígenas cuando se intente afectar a sus tierras ancestrales y sus recursos naturales, el matrimonio entre personas del mismo sexo, el derecho al agua y a su saneamiento, a un medio ambiente sano, a la paz, entre otros tanto más.

Las nuevas reivindicaciones que, de un modo continuo y consistente, se van manifestando en las sociedades desarrolladas del siglo XXI no son nuevas fronteras de los nuevos derechos humanos: un concepto casi necesariamente expansivo, destinado a ir adquiriendo nuevas competencias progresivamente, a ampliar su campo de acción de un modo irreversible a través de la historia ${ }^{37}$.

Los derechos humanos son prerrogativas de especie, que se han ido formando como parte de la cultura humana, se han otorgado y reconociendo a lo largo de la historia de la humanidad, sin que implique que por el hecho de que se legisle a favor de su exigencia jurídica se logre por sí mismo vigencia práctica.

Desde la convivencia pequeña entre dos personas o más o en las colectividades, hasta la creación de los Estados y esfuerzos internacionales no han sido suficiente para erradicar la desenfrenada ambición, ni la corrupción de los pseudo regímenes democráticos.

${ }^{37}$ HERNÁNDEZ CRUZ, Armando, Los derechos económicos, sociales y culturales y su justiciabilidad en el derecho mexicano, UNAM, México, 2010, p. 15. 
Instaurar las condiciones jurídicas para combatir la intolerancia ideológica, los atropellos, combatir la pobreza, erradicar cualquier tipo de esclavitud, la necesaria expedites en el acceso a la justicia eficaz, a la educación, a la protección de la salud, contar con vivienda digna, vivir en un entorno natural y adecuado para el desarrollo de la vida, el acceso al trabajo remunerado que permita adquirir satisfactores básicos como mínimo.

Una de las características de los derechos humanos es la progresividad o la no regresividad de los avances que se tengan en su protección, peculiaridad que se relaciona con el aspecto expansivo constante en el que se desarrollan.

[...] el Comité de Derechos Económicos, Sociales y Culturales de las Naciones Unidas ha señalado que "las medidas de carácter deliberadamente re[gresivo] en este aspecto requerirán la consideración más cuidadosa y deberán justificarse plenamente por referencia a la totalidad de los derechos previstos en el Pacto [Internacional de Derechos Económicos, Sociales y Culturales] y en el contexto del aprovechamiento pleno del máximo de los recursos de que [el Estado] disponga". En la misma línea, la Comisión Interamericana ha considerado que para evaluar si una medida regresiva es compatible con la Convención Americana, se deberá "determinar si se encuentra justificada por razones de suficiente peso" $[. . .]^{38}$.

Las corrientes filosóficas se han destacado en la explicación de lo que debe ser considerado como derecho y específicamente por los derechos humanos, son dos, la positivista, que determina que sólo es derecho aquel creado por los órganos legitimados de los Estados.

Es obvio que esta explicación tiene el interés para aquellas personas que detentan el poder, ya que éstas son las únicas que crean el derecho de acuerdo a sus intereses y con ello justificar las políticas sociales que imponen, cuyo argumento principal es el cumplimiento de las formas para procesar las leyes sin importar el contenido.

Otra, la denominada iusnaturalista, que es el margen o discurso de cualquier movimiento social que luche contra los gobernantes en turno, para que cambien las condiciones sociales, la cual afirma que existen determinados derechos que le corresponden al hombre sin necesidad de ser otorgados por el Estado, inclusive deben ser incluidos en las leyes del Estado, es decir, hacerse derecho positivo.

Los derechos humanos como consecuencia de la defensa del poder tienen su esencia en el derecho iusnaturalista.

38 CORTE IDH. Caso Acevedo Buendía y otros (“Cesantes y Jubilados de la Contraloría”) Vs. Perú. Excepción Preliminar, Fondo, Reparaciones y Costas. Sentencia de 1 de julio de 2009. Serie C No. 198, Párrafo 103. 
El iusnaturalismo o derecho natural ha sido un factor de cambio importante como los describe Gustav Radbruch:

\begin{abstract}
Abrió a la humanidad los ojos acerca de sus cadenas, enseñándole así a sacudírselas. Combatió el nombre del inalienable derecho humano de la libertad, la servidumbre, a la gleba y el vasallaje de los campesinos, la sumisión de la mujer casada al egoísmo del marido, el cautiverio del nombre de la ciudad a la jaula de oro de los gremios; mino el absolutismo de los gobiernos y los señoríos patrimoniales heredados del feudalismo, y combatió con armas de la seriedad y la burla del esclavizamiento de la libertad de los espíritus por las iglesias. Salvaguardó la personalidad contra la arbitrariedad de los abusos policíacos y proclamó la idea de Estado de Derecho, corrigió fundamentalmente al Derecho penal, al combatir la justicia basada en la arbitrariedad y establecer determinados tipos de delito incompatibles con la dignidad humana, las penas corporales de mutilación, acabó en el procedimiento criminal con el tormento y persiguió a los perseguidores de brujas. ${ }^{39}$
\end{abstract}

Los derechos humanos son un factor fundamental e importante para poder aspirar a realizar el ideal del ser humano libre, en el disfrute de las libertades civiles y políticas, liberado del temor y de la miseria, lo cual no es posible lograr a menos que se creen condiciones que permitan a cada persona gozar de los derechos económicos, sociales y culturales, como se establece los preámbulos del PIDCP y PIDESC.

\title{
4 ADMINISTRACIÓN PÚBLICA
}

La administración pública se organiza, dependiendo los intereses de quienes gobiernan y las necesidades de la población, en diversas instituciones: secretarías, órganos descentralizados, desconcentrados, fideicomisos, entre otras.

El artículo 26 de la Ley Orgánica de la Administración Pública en México prevé para el despacho de los asuntos del orden administrativo, que el Poder Ejecutivo de la Unión contará con las dieciocho dependencias, entre ellas, la Secretaría de Bienestar cuyas funciones, entre otras, son fortalecer el bienestar, el desarrollo, la inclusión y la cohesión social en el país mediante la instrumentación, coordinación, supervisión y seguimiento, de las políticas de combate efectivo a la pobreza; atención específica a las necesidades de los sectores sociales más desprotegidos, en especial de los pobladores de las zonas áridas de las áreas rurales, así como de los colonos y marginados de las áreas urbanas; y la atención preponderante a los

39 RADBRUCH, Gustav, Introducción a la filosofía del derecho, Fondo de Cultura Económica, México, 2005, p. 112. 
derechos de la niñez, de la juventud, de los adultos mayores, de los pueblos indígenas y de las personas con discapacidad; impulsar políticas y dar seguimiento a los programas de inclusión social y protección de los derechos de niñas, niños y adolescentes; elaborar políticas públicas y dar seguimiento a los programas de apoyo e inclusión de los jóvenes a la vida social participativa y productiva; coadyuvar en las políticas públicas que garanticen el pleno ejercicio de los derechos y el desarrollo de los pueblos indígenas.

Es la administración pública a la que le corresponde realizar una serie importante de prestaciones para cumplir con los derechos humanos. El vocablo administración tiene su raíz etimológica en el latinismo administrativo que significa acción o efecto de administrar que a su vez proviene del verbo latino administrar y que se define como gobernar, ejercer autoridad o el mando en un territorio y sobre las personas que lo habitan ${ }^{40}$.

\subsection{Coordinación de departamentos en la administración pública}

El Comité de los Derechos del Niño durante el examen de los informes de los Estados parte, ha considerado necesario alentar una mayor coordinación de los poderes públicos con miras a garantizar la aplicación efectiva: coordinación entre los departamentos de la administración central, entre las diferentes provincias y regiones, entre la administración central y otros niveles de la administración y entre los poderes públicos y la sociedad civil. La finalidad de la coordinación es velar por que se respeten todos los principios y normas enunciados en la Convención sobre los Derechos del Niño (CDN) para todos los niños sometidos a la jurisdicción del Estado; hacer que las obligaciones dimanantes de la ratificación de la CDN o de la adhesión a ésta, sean reconocidas no sólo por los principales departamentos cuyas actividades tienen considerables repercusiones sobre los niños (en las esferas de la educación, de la salud, del bienestar, etc.), sino también por todos los poderes públicos, incluidos, por ejemplo, los departamentos que se ocupan de las finanzas, de la planificación, del empleo y de la defensa, en todos los niveles. ${ }^{41}$

\footnotetext{
${ }^{40}$ SCJN, Manual del justiciable. Materia administrativa, México, 2004, p. 11.

41 Observación: CRC-GC-5 Medidas generales de aplicación de la Convención sobre los derechos del niño, Párr. 37.
} 


\subsection{Participación de la mujer en la administración pública}

El Comité de los Derechos Humanos ha señalado que el derecho a participar en la vida pública no se materializa plenamente y en condiciones de igualdad. Los Estados parte deben cerciorarse de que la ley garantice a la mujer los derechos en pie de igualdad con el hombre y adoptar medidas eficaces y positivas, incluida las medidas necesarias de discriminación inversa, para promover y asegurar la participación de la mujer en los asuntos públicos y en el ejercicio de cargos públicos. Las medidas efectivas que adopten deben velar porque todas las personas con derecho al voto puedan ejercerlo, sin discriminación por razones de sexo. El Comité pide a los Estados parte que presenten información estadística acerca del porcentaje de mujeres que desempeñan cargos de elección pública, con inclusión del poder legislativo y de altos cargos en la administración pública y el poder judicial. ${ }^{42}$

Es factible señalar que la administración pública es el instrumento fundamental de la eficacia de los derechos humanos, toda vez que la razón de la primera es hacer real la atención de las necesidades de desarrollo de la sociedad.

La administración pública aparece desde que el hombre se organiza en sociedades, más o menos complejas, en que se distingue la presencia de una autoridad, que subordina y rige actividades del resto del grupo y que se encarga de proveer la satisfacción de las necesidades colectivas fundamentales ${ }^{43}$.

Los derechos humanos se constituyen en el fundamento ético de la formulación y ejecución de políticas públicas. Los derechos humanos son el objeto mismo de las políticas públicas en la medida a que éstas se dirigen a la concreción, protección o defensa de situaciones socialmente relevantes que implican violación o vulneración derechos humanos ${ }^{44}$.

\section{CONCLUSIÓN}

Es factible designar que el cumplimiento de los derechos humanos de fuente constitucional y convencional implica necesariamente el establecimiento del Estado social y democrático de los derechos humanos, bajo los principios de universalidad, interdependencia,

42 Observación: CCPR-GC-28 La igualdad de derechos entre hombres y mujeres (Sustituye la CCPR/GC/4), Párr. 29.

43 OSORIO CORRES, Francisco Javier, voz "administración pública" en Diccionario jurídico mexicano, t. ACh, $5^{a}$ edición, Porrúa-UNAM, México, 1995, p. 107.

44 JIMÉNEZ BENÍTEZ, William Guillermo, op. cit. p. 123. 
indivisibilidad y progresividad, cuya parte fundamental de su eficacia corresponde a la esfera administrativa, recuperando áreas que había abandonado durante el neoliberalismo.

La evolución del Estado de derecho al social y democrático de los derechos humanos, sin dejar de señalar estadios intermedios, responde a la necesidad social de recuperar y crear áreas de la administración pública que tengan como función esencial impulsar el desarrollo humano sin distinción.

El Estado nacional se ha ido trasformando a través del derecho convencional de los derechos humanos, principalmente en un ente cuya tarea principal es tutelar dentro de su jurisdicción los derechos humanos de la población. Esta función se ha ido dinamizando y perfeccionando no por las disposiciones internas, sino por los tratados internacionales, encauzando la labor del Estado a tareas que antes eran consideradas programáticas, generales, sin instrumentos claros de aplicación.

La administración pública es la herramienta fundamental del Estado para lograr la vigencia plena de los derechos humanos, no el mercado, por la diferencia radical de las funciones e interés de cada uno.

\section{REFERENCIAS}

ÁLVAREZ-BRAVO, Paulo. Educación y derechos humanos en Chile: una relación necessária. Revista Educación, v. 43, n. 1, 2019. Disponible en:

https://revistas.ucr.ac.cr/index.php/educacion/article/view/29966. Acceso el: 07 jul. 2020.

BALLESTEROS LLOMPART, Jesús et. al. Derechos Humanos. Valencia: Universidad de Valencia, 2007.

BALLESTEROS LLOMPART, Jesús; FERNÁNDEZ RUIZ- GÁLVEZ ENCARNACIÓN; GARIBO PEYRÓ, Ana Paz. Derechos humanos. España: Universitat de Valéncia, 2007.

BAUTISTA, Felix. Estado social y democrático de derecho. Listín Diario, 01 de febrero de 2012. Disponible en: https: / / listindiario.com/puntos-de-vista/2012/02/01/220146/estado-social-ydemocratico-de-derecho. Acceso el: 02 jul. 2020.

BOBBIO, Norberto. El futuro de la democracia. México: Fondo de Cultura Económica, 1991.

BOURDIEU, Pierre. La esencia del neoliberalismo. Revista Colombiana de Educación, n. 35, 1997. Disponible en:

https://revistas.pedagogica.edu.co/index.php/RCE/article/view/5426/4453. Acceso el: 02 jul. 2020. 
CARPIZO, Jorge. Los derechos humanos: naturaleza, denominación y características. Cuestiones constitucionales, n. 25, 2011. pp. 3-29.

CORTE INTERAMERICANA DE DERECHOS HUMANOS. Caso Acevedo Buendía y otros ("Cesantes y Jubilados de la Contraloría") Vs. Perú. Excepción Preliminar, Fondo, Reparaciones y Costas. Sentencia de 1 de julio de 2009. Serie C, n. 198. Disponible en:

https://www.corteidh.or.cr/docs/casos/articulos/seriec_198_esp.pdf. Acceso el: 07 jul. 2020.

CORTE INTERAMERICANA DE DERECHOS HUMANOS. Caso Atala Riffo y Niñas Vs. Chile. Fondo, Reparaciones y Costas. Sentencia del 24 de febrero de 2012. Serie C, n. 239. Disponible en: https://corteidh.or.cr/docs/casos/articulos/seriec_239_esp.pdf. Acceso el: 07 jul. 2020.

CORTE INTERAMERICANA DE DERECHOS HUMANOS. Caso Cantoral Benavides Vs. Perú. Fondo. Sentencia de 18 de agosto de 2000. Serie C, n. 69. Disponible en:

https://www.corteidh.or.cr/docs/casos/articulos/Seriec_69_esp.pdf. Acceso el: 07 jul. 2020.

EYNER ISAZA, Henry. Los derechos humanos y Sistema Interamericano. Bogotá: Ediciones Nueva Jurídica, 2014.

FONDO DE LAS NACIONES UNIDAS PARA LA INFANCIA. Observación General N 5: Medidas generales de aplicación de la Convención sobre los Derechos del Niño. 2003. Disponible en: https: / / www.unicef.org/UNICEF-ObservacionesGeneralesDelComiteDeLosDerechosDelNinoWEB.pdf. Acceso el: 07 jul. 2020.

GALIANO HAENCH, José. Derecho humanos. Teoría, historia, vigencia y legislación. Santiago de Chile: LOM-ARCIS Universidad, 1998.

GALLARDO LEÓN, Ernesto. El problema de la representación en El Quijote; In: CONSTANTE, Alberto; SAISÓ, Ernesto Priani; CHOREÑO, Rafael Ángel Gómez (Orgs.). Michel Foucault: Reflexiones sobre el saber, el poder, la verdad y las prácticas de sí. México: UNAM, 2008. p. 714. Disponible en:

http://ru.ffyl.unam.mx/jspui/bitstream/handle/10391/323/Libro\%20Michel\%20Foucault.pdf?seq uence=6\&isAllowed=y. Acceso el: 07 jul. 2020.

GUTIÉRREZ Y GONZÁLEZ, Ernesto. El patrimônio. México: Porrúa, 1995.

GUTIÉRREZ, Diana Carolina Sánchez; RICAUTE, Sandra Patricia; CASTILLO, David Felipe.

Compatibilidad del princípio de sostenibilidad fiscal y el concepto de estado social de Derecho en Colombia. Vestigium Ire, vol. 5, no. 1, 2012.

HERNÁNDEZ CRUZ, Armando. Los derechos económicos, sociales y culturales y su justiciabilidad en el derecho mexicano. México: UNAM, 2010.

LARRAÑAGA, Osvaldo, et al. ¿Qué puede esperarse de la política social en Chile? Documento de Investigación del Departamento de Economía, Universidad de Chile, 2007.

MARTÍNEZ LAZCANO, Alfonso Jaime. Sistemas regionales de protección de derechos humanos. Bogotá: Ediciones Nueva Jurídica, 2015. 
MÉXICO. Constitución Política de los Estados Unidos Mexicanos de 1917. In: Diario Oficial de la Federación, 5 de febrero de 1917. Disponible en:

http://www.diputados.gob.mx/LeyesBiblio/pdf_mov/Constitucion_Politica.pdf. Acceso el: 07 jul. 2020.

MÉXICO. Ley Orgánica de la Administración Pública. In: Diario Oficial de la Federación: 22 De enero de 2020. Disponible en:

http://www.ordenjuridico.gob.mx/Documentos/Federal/pdf/wo13235.pdf. Acceso el: 07 jul. 2020.

MÉXICO. Suprema Corte de Justicia. Amparo directo en revisión 2524/2015. Dignidad humana. Constituye una norma jurídica que consagra un derecho fundamental a favor de las personas y no una simple declaración ética. Ejecutoria 1a./J. 37/2016 (10a). 31 de agosto de 2016. Disponible en: https://suprema-corte.vlex.com.mx/vid/652458081. Acceso el: 08 jul. 2020.

MÉXICO. Suprema Corte de Justicia. Estado regulador. Parámetro constitucional para determinar la validez de sus sanciones. Tesis Aislada 1a. CCCXVII/2014 (10a). 30 de septiembre de 2014. Disponible en: https://suprema-corte.vlex.com.mx/vid/tesis-aisladas-528053814. Acceso el: 08 jul. 2020.

MORA, Patricia Bastidas. El modelo constitucional del Estado Social y democrático de derecho, sus desafíos y la constitucionalización del processo. Revista Via luris, n. 7, 2009. pp. 45-59.

MORENO, Luis. Ciudadanía, desigualdad social y Estado del bienestar. Unidad de Políticas Comparadas (CSIC), 2003. Disponible en: https://core.ac.uk/download/pdf/36013923.pdf. Acceso el: 02 jul. 2020.

ORGANIZACIÓN DE LAS NACIONES UNIDAS. Declaración Universal de Derechos del Hombre. 1948. Disponible en: https://www.ohchr.org/EN/UDHR/Documents/UDHR_Translations/spn.pdf. Acceso el: 07 jul. 2020.

ORGANIZACIÓN DE LAS NACIONES UNIDAS. Derechos Humanos. Disponible en: http://un.org/es/rights/overview. Acceso el: 02 jul. 2020.

ORGANIZACIÓN DE LAS NACIONES UNIDAS. Observación general $n^{\circ}$ 28: La igualdad de derechos entre hombres y mujeres (Sustituye la CCPR/GC/4). 2000. Disponible en: https://tbinternet.ohchr.org/Treaties/CCPR/Shared\%20Documents/1_Global/CCPR_C_21_Rev1_Add-10_6619_S.pdf. Acceso el: 07 jul. 2020.

ORGANIZACIÓN DE LAS NACIONES UNIDAS. Oficina del Alto Comisionado. ¿Qué son los derechos humanos? Disponible en: http://www.ohchr.org/SP/Issues/Pages/WhatareHumanRights.aspx. Acceso el: 02 jul. 2020.

ORGANIZACIÓN DE LAS NACIONES UNIDAS. Pacto Internacional de Derechos Civiles y Políticos. 1976. Disponible en: https://www.ohchr.org/sp/professionalinterest/pages/ccpr.aspx. Acceso el: 07 jul. 2020.

ORGANIZACIÓN DE LAS NACIONES UNIDAS. Pacto Internacional de Derechos Económicos, Sociales y Culturales. 1976. Disponible en: https://www.ohchr.org/SP/Professionallnterest/Pages/CESCR.aspx. Acceso el: 07 jul. 2020. 
ORGANIZACIÓN DE LOS ESTADOS AMERICANOS. Declaración Americana de Derechos y Deberes del Hombre. 1948. Disponible en:

https://www.oas.org/dil/esp/Declaraci\%C3\%B3n_Americana_de_los_Derechos_y_Deberes_del_H ombre_1948.pdf. Acceso el: 07 jul. 2020.

ORGANIZACIÓN MUNDIAL DE LA SALUD. Derechos humanos. Disponible en: http://www.who.int/topics/human_rights/es/. Acceso el: 06 jul. 2020.

OSORIO CORREA, Francisco Javier. Voz administración pública. In: Diccionario jurídico mexicano. 5. ed. México: Porrúa-UNAM, 1995.

PECES-BARBA MARTÍNEZ, Gregorio. Los valores superiores. 1987, p.375. (Véase en: https://earchivo.uc3m.es/bitstream/handle/10016/10389/valores_Peces_AFD_1987.pdf?sequence=1, , consulta 12/12/2019).

QUINTANA ROLDÁN, Carlos; SABINO PENICHE, Norma. Derechos humanos. Porrúa: México, 2013.

RADBRUCH, Gustav. Introducción a la filosofía del derecho. México: Fondo de Cultura Económica, 2005.

SUPREMA CORTE DE JUSTICIA DE LA NACIÓN. Manual del justiciable. Materia administrativa. México, 2004. Disponible en:

https://www.academia.edu/38083656/Manual_del_Justiciable_Materia_Administrativa_SCJN. Acceso el: 07 jul. 2020.

STOLKINER, Alicia. Derechos humanos y derecho a la salud en América Latina: la doble faz de una idea potente. Medicina social, v. 5, n. 1, 2010. pp. 89-95.

TAMI, Felipe; SALVIA, Agustín. Introducción: desarrollo humano y deuda social. In: Barómetro de la Deuda Social Argentina, v. 1 [Las Grandes Desigualdades]. Buenos Aires

(Argentina): EDUCA, 2004. Disponible en: https://www.aacademica.org/agustin.salvia/181.pdf. Acceso el: 06 jul. 2020.

VARGAS HERNÁNDEZ, José Guadalupe. Liberalismo, neoliberalismo y postneoliberalismo. In: II Jornadas de Investigación em Humanidades, 2007. Disponible en:

http://200.49.237.216/bitstream/123456789/3361/1/Vargas\%20Hernandez\%20-

\%20liberalismo.pdf. Acceso el: 06 jul. 2020.

ZAMUDIO, Teodora. Historia de los Bio-Derechos y del pensamiento bioético. Derechos humanos y pactos internacionales. Disponible en:

http://www.bioetica.org/cuadernos/contenidos/pactos.htm. Acceso el: 05 jun. 2020.

ZUNIGA QUEVEDO, Javier. La desigualdad en América Latina. Panorámica, 30 de enero de 2020. Disponible en: https: / /www.panoramical.eu/columnas/la-desigualdad-en-america-latina/.

Acceso el: 06 jul. 2020.

Artigo convidado / Publicado em: 15.07.2020 


\section{COMO FAZER REFERÊNCIA AO ARTIGO (ABNT / BRASIL):}

LAZCANO, Alfonso Jaime Martínez. Direitos humanos no Estado social e democrático. Revista Eletrônica do Curso de Direito da UFSM, Santa Maria, RS, v. 15, n. 2, e48166, maio/ago. 2020. ISSN 1981-3694. DOI: http://dx.doi.org/10.5902/1981369448166. Disponível em:

https://periodicos.ufsm.br/revistadireito/article/view/48166 Acesso em: dia mês. ano.

Direitos autorais 2020 Revista Eletrônica do Curso de Direito da UFSM

Editores responsáveis: Rafael Santos de Oliveira e Angela Araujo da Silveira Espindola

\section{c) (i) $(9$ \\ BY NC ND}

Esta obra está licenciada com uma Licença Creative Commons Atribuição-NãoComercial-SemDerivações 4.0 Internacional.

\section{SOBRE O AUTOR}

\section{ALFONSO JAIME MARTÍNEZ LAZCANO}

Doctor en Derecho Público. Profesor e Investigador en la Universidad Autónoma de Chiapas - México. Presidente del CAPL. Director de la Revista Jurídica Primera Instancia. Vicepresidente de Investigaciones de la Asociación Mundial de Justicia Constitucional. 